ARTICLE

\title{
A persistently low level of atmospheric oxygen in Earth's middle age
}

\author{
Xiao-Ming Liu ${ }^{1 凶}$, Linda C. Kah ${ }^{2}{ }^{2}$, Andrew H. Knoll ${ }^{3}$, Huan Cui ${ }^{4,5}$, Chao Wang ${ }^{1}$, Andrey Bekker ${ }^{6,7}$ \&
} Robert M. Hazen ${ }^{8}$

Resolving how Earth surface redox conditions evolved through the Proterozoic Eon is fundamental to understanding how biogeochemical cycles have changed through time. The redox sensitivity of cerium relative to other rare earth elements and its uptake in carbonate minerals make the $\mathrm{Ce}$ anomaly $\left(\mathrm{Ce} / \mathrm{Ce}^{\star}\right)$ a particularly useful proxy for capturing redox conditions in the local marine environment. Here, we report $\mathrm{Ce} / \mathrm{Ce}^{\star}$ data in marine carbonate rocks through 3.5 billion years of Earth's history, focusing in particular on the mid-Proterozoic Eon (i.e., $1.8-0.8 \mathrm{Ga}$ ). To better understand the role of atmospheric oxygenation, we use $\mathrm{Ce} /$ $\mathrm{Ce}^{\star}$ data to estimate the partial pressure of atmospheric oxygen $\left(\mathrm{pO}_{2}\right)$ through this time. Our thermodynamics-based modeling supports a major rise in atmospheric oxygen level in the aftermath of the Great Oxidation Event $(\sim 2.4 \mathrm{Ga})$, followed by invariant $\mathrm{pO}_{2}$ of about $1 \%$ of present atmospheric level through most of the Proterozoic Eon (2.4 to $0.65 \mathrm{Ga}$ ).

\footnotetext{
${ }^{1}$ Department of Geological Sciences, University of North Carolina, Chapel Hill, NC 27599, USA. ${ }^{2}$ Department of Earth and Planetary Sciences, University of Tennessee, Knoxville, TN 37996, USA. ${ }^{3}$ Department of Organismic and Evolutionary Biology, Harvard University, Cambridge, MA 02138, USA. ${ }^{4}$ Department of Earth Sciences, University of Toronto, Toronto, ON M5S 3B1, Canada. ${ }^{5}$ Geomicrobiology Group, Institut de Physique du Globe de Paris, University of Paris, 75005 Paris, France. ${ }^{6}$ Department of Earth and Planetary Sciences, University of California, Riverside, CA 92521, USA. ${ }^{7}$ Department of Geology, University of Johannesburg, Auckland Park, Johannesburg 2006, South Africa. ${ }^{8}$ Earth and Planets Laboratory, Carnegie Institution for Science, Washington, DC 20015, USA. ${ }^{凶}$ email: xiaomliu@unc.edu
} 
E arth's $\mathrm{O}_{2}$-rich atmosphere, unique among known planets, has played an essential role in the evolving feedbacks between life and the environment. The Proterozoic Eon, nearly 2 billion years in duration, has long been characterized in terms of two major episodes of oxygenation, the Great Oxidation Event (GOE) near the beginning of the eon and the Neoproterozoic Oxidation Event (NOE) near its end ${ }^{1,2}$. Between these two events, however, the level of oxygen in the atmosphere and surface ocean, as well as the vertical distribution of oxygen in the oceans, remains a topic of debate. Recently, several attempts have been made to constrain the atmospheric oxygen levels during the mid-Proterozoic. For example, biomarkers from the ca. $1.4 \mathrm{Ga}$ Xiamaling Formation, China, have been interpreted in terms of partial pressure of atmospheric $\mathrm{O}_{2}>4$ to $8 \% \mathrm{PAL}^{3-5}$. These values are consistent with previous estimates of the midProterozoic atmospheric. $\mathrm{O}_{2}$ levels based on paleosol records ${ }^{1,6}$; however, and other geochemical tracers ( $\mathrm{Cr}$ isotopes and $\mathrm{Ce}$ anomalies) in marine sedimentary records seem to suggest lower $\mathrm{pO}_{2}(<0.1-1 \% \mathrm{PAL})^{7-9}$. Additional geochemical proxy data from marine carbonate phases suggest atmospheric $\mathrm{O}_{2}$ levels intermediate between these estimates ${ }^{10,11}$. Most of these studies were based on individual stratigraphic units and did not provide long term estimates of $\mathrm{pO}_{2}$ through time. Thus, there remains considerable uncertainty in atmospheric $\mathrm{O}_{2}$ level, the degree to which it may have varied through the Proterozoic, and its effects on marine oxygenation and life. Constraining atmospheric oxygen concentration is thus a critical step in understanding the extent to which ocean redox through time was coupled with, or decoupled from, atmospheric evolution ${ }^{12,13}$. Consequently, new quantitative approaches are needed to construct a continuous record of $\mathrm{O}_{2}$ level in the mid-Proterozoic atmosphere.

Because marine carbonate rocks incorporate rare earth elements plus yttrium (REE+Y, or REY), REYs have long been used as a paleoredox tracer for ancient shallow-marine environments $^{14,15}$. The cerium anomaly, designated as $\mathrm{Ce} / \mathrm{Ce}^{*}$ (where $\mathrm{Ce} / \mathrm{Ce}^{*}=\mathrm{Ce} \times \mathrm{Nd} / \mathrm{Pr}^{2} ;{ }^{16}$ ), is used routinely to delineate the differential redox behavior of Ce relative to its neighboring REEs and thus fingerprints oxic versus anoxic depositional conditions ${ }^{14,15}$. Under oxic conditions, $\mathrm{Ce}$ is preferentially removed from the water column through scavenging by manganese oxides and hydroxides ${ }^{17}$, resulting in a negative anomaly $\left(\mathrm{Ce} / \mathrm{Ce}^{*}<1\right)$. Under suboxic or anoxic conditions of the modern ocean, Ce anomalies are weak to absent, reflecting the reductive dissolution of Mn-rich and Fe-rich particles below the redoxcline $\mathrm{e}^{18,19}$; therefore, $\mathrm{Ce} / \mathrm{Ce}^{*}$ shifts closer to 1 . For this reason, $\mathrm{Ce}$ anomalies are useful for distinguishing oxic depositional environments from suboxic and anoxic settings ${ }^{20}$.

Recently, REYs in marine carbonates have been used as a proxy for past atmospheric oxygen levels ${ }^{7,21}$ by assuming that the oxygen content of well-mixed surface seawater is in equilibrium with the overlying atmosphere. Wallace et al. ${ }^{21}$ focused on Ce/ $\mathrm{Ce}^{*}$ in a compilation of marine carbonate rocks deposited between $760 \mathrm{Ma}$ and the present. Bellefroid et al. ${ }^{7}$, in turn, compiled $\mathrm{Ce} / \mathrm{Ce}^{*}$ data from 1.6 to $0.5 \mathrm{Ga}$, including data from Wallace et $\mathrm{al}^{21}$, and generated new measurements for $\sim 1.9 \mathrm{Ga}$ platform carbonates from Great Slave Lake, Canada. The modeling performed by Bellefroid et al. ${ }^{7}$ was based on Ce oxidation kinetics, combining water-mass residence time with Ce oxidation and particle adsorption rates. Limited understanding of Ce oxidation kinetics, however, required Bellefroid et al. ${ }^{7}$ to make several assumptions, including critical parameters such as dust flux, particle sinking rate, the redox structure of the mid-Proterozoic ocean, and Ce residence time at different depositional depths. More importantly, they used a global circulation model for the modern ocean to calculate key parameters in the Proterozoic ocean. By contrast, thermodynamics-based Ce oxidation has been widely studied (Supplementary Discussion) ${ }^{22}$, and provides a complementary approach to kinetics-based modeling that requires a number of subjective assumptions. Indeed, a thermodynamics-based approach using Ce data for modern settings generates atmospheric oxygen estimates that are close to the modern atmospheric oxygen level ${ }^{23}$.

This work uses the thermodynamic behavior of $\mathrm{Ce} / \mathrm{Ce}^{*}$ incorporated into shallow-marine carbonate rocks to quantify ancient atmospheric oxygen levels, focusing mainly on midProterozoic samples (i.e., 1.8-0.8 Ga; broadly between the GOE and the NOE), for which previous estimates of atmospheric oxygen vary markedly. In modeling new and existing data, we make four principal assumptions: 1) shallow-marine environments are well-mixed and in equilibrium with the atmosphere in terms of dissolved oxygen; 2) $\mathrm{Ce}^{3+}, \mathrm{Pr}^{3+}$, and $\mathrm{Nd}^{3+}$ have similar solubilities in the oceans; 3 ) the relative partitioning of Ce vs. $\mathrm{Pr}$ and $\mathrm{Nd}$ into carbonate minerals has remained the same through time; and 4) oxidation of $\mathrm{Ce}^{3+}$ to $\mathrm{Ce}^{4+}$, inhibits incorporation into carbonate, whereas $\mathrm{Pr}$ and $\mathrm{Nd}$ are trivalent and their incorporation behavior is redox-independent.

\section{Results}

Sample selection and data filtering. In all carbonate samples, the potential for diagenetic alteration is of concern. Fortunately, previous studies provide strong evidence that 1) non-skeletal carbonates can faithfully record the REE composition of ambient seawater ${ }^{15,24}$ and 2) REEs in carbonate rocks are relatively immobile during fluid-rock interaction and can retain a seawater signature even after dolomitization ${ }^{24,25}$, the most widespread diagenetic process to affect carbonate rocks. To limit the potential for carbonate alteration, we selected units with known sedimentological and stratigraphic context, and further investigated the potential for diagenesis via petrographic analysis and elemental and isotope geochemistry. Samples used in this study primarily consist of finely crystalline limestone and penecontemporaneous, fabricretentive dolostone associated with petrographically well-preserved marine precipitates (e.g., micrite, microbialites, and marine cement). All sample powders were micro-drilled from polished thick sections to avoid clearly altered phases, secondary vein mineralization, and areas with visible non-carbonate phases.

Even with a carefully selected sample set, the high reactivity of sedimentary carbonate minerals indicates that these samples could have been affected by both syndepositional diagenesis at or near the sediment-water interface and water-rock interactions during burial. Such diagenetic influences can contribute to the local variation of $\mathrm{Ce} / \mathrm{Ce}^{*}$ (Fig. 1). We acknowledge that all carbonates are therefore likely to have undergone at least some degree of diagenesis, which generally decreases the negative $\mathrm{Ce}$ anomaly (increasing $\mathrm{Ce} / \mathrm{Ce}^{*}$ values) ${ }^{24}$. In addition, modern oxidative weathering could result in large positive or negative variations in the $\mathrm{Ce}$ anomaly on a small spatial scale ${ }^{26}$. In consequence, we expect that these post-depositional alteration processes would increase the variance of $\mathrm{Ce} / \mathrm{Ce}^{*}$ within individual time intervals. Additionally, because REY has a short residence time in seawater, typically less than 1000 years ${ }^{27}$, variation in observed $\mathrm{Ce} / \mathrm{Ce}$ * can also reflect basin restriction and a decrease in mixing with open-marine surface water. Moreover, Ce anomalies show vertical variability in modern oceans, reflecting dissolved oxygen concentration (see e.g. ${ }^{28}$ ). Thus, differences in water depth recorded by shallow-marine carbonates can also contribute to observed $\mathrm{Ce} / \mathrm{Ce}{ }^{*}$ variation in the dataset, although essentially all of our samples are inferred to have been deposited beneath well-mixed surface water masses. Therefore, selecting samples from relatively shallow-marine settings reduced risk of significant depth influence on the measured $\mathrm{Ce}$ anomalies. 


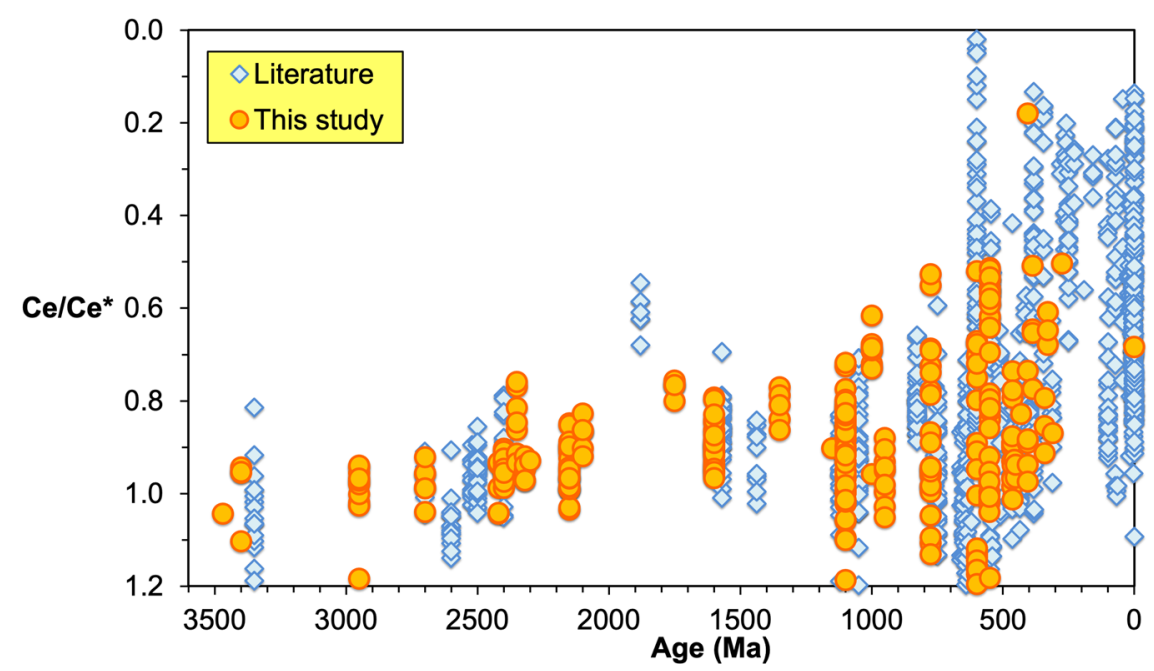

Fig. 1 Secular trend of $\mathbf{C e}$ anomaly $\left(\mathbf{C e} / \mathbf{C e}^{\star}\right)$ in marine carbonates. The figure contains $>1300$ data points for $\mathrm{Ce}$ anomaly, including literature data (blue diamonds) and our 305 new analyses (orange circles).

In addition to diagenesis, basin restriction, depositional depth, and sample preparation and dissolution can impact the REE signal because carbonate rocks can contain non-carbonate phases such as clay, iron, and manganese (oxyhydr)oxides. Noncarbonate phases could significantly influence the REY concentrations and reduce the magnitude of $\mathrm{Ce}$ anomalies, requiring dissolution methods that attack predominantly authigenic carbonate $^{29,30}$. Besides the effects of diagenesis and depositional depth, we consider that non-carbonate contamination has an important impact on $\mathrm{Ce}$ anomaly in ancient carbonates. Noncarbonate contamination generally decreases deviation from the non-fractionated $\mathrm{Ce} / \mathrm{Ce}^{*}$ value of $1^{24}$; this effect is difficult to exclude from the literature data that we compiled due to a large range of analytical methods and leaching protocols involved. We thus infer that the trend in the lowest $\mathrm{Ce} / \mathrm{Ce}^{*}$ data, rather than mean values, is most likely to record a true secular change.

We also consider the potential influence of carbonate mineralogy on Ce anomaly data. To address that, we plotted all carbonate samples based on their mineralogy in Supplementary Fig. 3; these data show that there is no systematic difference in $\mathrm{Ce} / \mathrm{Ce}^{*}$ values between limestone and dolostone through time. This similarity likely reflects the observation that Proterozoic dolostone typically formed at or near the sediment-water interface, preserving depositional or near-depositional geochemical signatures (e.g., see ref. ${ }^{31}$ ); neomorphosed limestones (i.e., those that underwent penecontemporaneous recrystallization within the depositional environment) also appear to preserve seawater REE signatures ${ }^{32}$.

In addition to reported geological, petrographic, and geochemical criteria, we further filtered samples based on individual REY patterns and Y/Ho ratios (e.g., see ref. ${ }^{19,30}$, see also Supplementary Discussion), which could indicate potential post-depositional alteration and non-carbonate phase contamination where such data were available. In this study, we have analyzed more than 400 ancient carbonate rocks, but only 305 samples passed our combined REY and Y/Ho filter criteria (Supplementary Discussion). The only literature exceptions are data from Wallace et al. ${ }^{21}$, where we directly used their reported Ce anomaly data without further filtering. After filtering, we report $\mathrm{Ce} / \mathrm{Ce} *$ from more than 1300 samples, focusing primarily on Proterozoic carbonate samples (see Supplementary Dataset 1). Limited data available for some published studies, specifically where $\mathrm{Y}$ or Ho concentrations were not reported, did not permit data filtering.

\section{Discussion}

Our compilation of $\mathrm{Ce} / \mathrm{Ce}^{*}$ in marine carbonate rocks is displayed in Fig. 2, with a curve fit to the lowest $10 \%$ of $\mathrm{Ce} / \mathrm{Ce}^{*}$ values in every $100 \mathrm{Myr}$ interval. Similar to previous compilations, our data show a trend of increasing magnitude of negative Ce anomalies towards the GOE and a broad, though modest, increase in the latter part of the mid-Proterozoic interval that accelerated into a marked Ediacaran to mid-Paleozoic change. The slight increase in the negative Ce anomaly after the GOE likely reflects an increased atmospheric oxygen level. In turn, the invarient $\mathrm{Ce}$ anomaly in the late Paleoproterozoic to midProterozoic interval suggests that global redox conditions did not increase significantly or irreversibly between the GOE and NOE. The abrupt excursion in the late Neoproterozoic agrees with the timing of the NOE, while the dramatic increase in the lower to middle Paleozoic $\left(\sim 400 \mathrm{Ma}^{25}\right)$ is consistent with independent inferences of whole-scale ocean oxygenation at this time ${ }^{33,34}$.

We use $\mathrm{Ce} / \mathrm{Ce}^{*}$ data to quantify atmospheric oxygen levels after the GOE because $\mathrm{Ce} / \mathrm{Ce}^{*}$ is sensitive to distinguishing oxic from suboxic and anoxic environments ${ }^{20}$. Using our compiled $\mathrm{Ce} / \mathrm{Ce}^{*}$ carbonate data and a thermodynamics-based Ce oxidization model, we provide quantitative estimates of Earth's atmospheric oxygen evolution after the GOE. Details of the equations and their derivations are provided in Supplementary Discussion. Using the presence of marine carbonate since at least $\sim 2.9 \mathrm{Ga}$ as evidence for buffered marine $\mathrm{pH}$, we infer that $\mathrm{pH}$ of the ocean has not changed significantly since the Proterozoic Eon. Nonetheless, small $\mathrm{pH}$ change could influence $\mathrm{pO}_{2}$ estimate. Thus, we include a sensitivity test of $\mathrm{pH}$ in Supplementary Discussion to demonstrate that previously suggested $\mathrm{pH}$ range does not significantly impact our conclusions. The influence of temperature on the equilibrium constant $(\mathrm{K})$ in low-temperature surface processes is minor. Therefore, we assume that neither $\mathrm{pH}$ nor K changed significantly since the beginning of the Proterozoic in ways, that would significantly affect our conclusions. We can then simplify the relationship between $\mathrm{Ce} / \mathrm{Ce}^{*}$ and $\mathrm{pO}_{2}$ by assuming that the relationship between modern atmospheric $\mathrm{pO}_{2}$ and modern seawater $\mathrm{Ce} / \mathrm{Ce}^{*}$ is reflected in the $\mathrm{Ce} / \mathrm{Ce}^{*}$ values of the present-day shallow-marine carbonates. Assuming a similar relationship between past carbonate $\mathrm{Ce} / \mathrm{Ce}^{*}$ values and atmospheric $\mathrm{pO}_{2}$, we can calculate $\mathrm{pO}_{2}$ for any given time in Earth's history from $\mathrm{Ce} / \mathrm{Ce}^{*}$ values preserved in shallow-marine carbonate deposited at that time. 


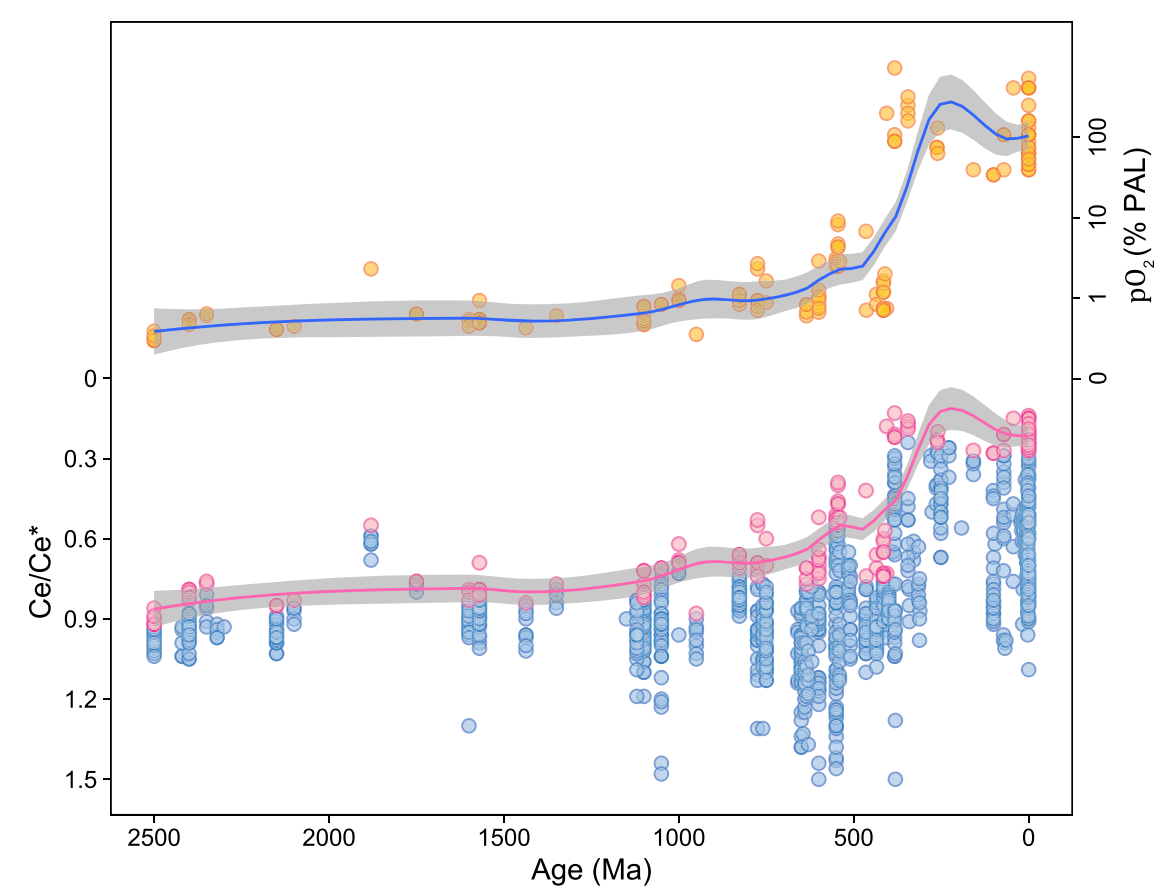

Fig. 2 Estimated partial pressure of atmospheric oxygen and Ce anomaly through Earth's history. Lower part: $\mathrm{Secular}$ trend of $\mathrm{Ce}$ anomaly $\left(\mathrm{Ce} / \mathrm{Ce} \mathrm{e}^{\star}\right)$ for all complied carbonate data with fitting to lowest $10 \%$ of the data shown in pink circles. The pink line indicates the best fit for $100 \mathrm{Ma}$ intervals using the Local Polynomial Regression (LOESS) curve fitting method and the gray field indicates the upper and lower bounds based on $95 \%$ confidence level. Upper part: Estimated partial pressure of atmospheric oxygen, $\mathrm{pO}_{2}$ (\% PAL), through Earth's history. The blue line shows our best estimate, and the gray field indicates the upper and lower bounds based on $95 \%$ confidence level using the LOESS curve fitting method. The $\mathrm{pO}_{2}$ was calculated using the lowest $10 \%$ of all carbonate $\mathrm{Ce} / \mathrm{Ce}^{\star}$ data for $100 \mathrm{Ma}$ intervals.

Table 1 Atmospheric oxygen level estimates based on the discrete method.

\begin{tabular}{|c|c|c|c|c|}
\hline Group & Age & $\begin{array}{l}5 \text { percentiles } \\
\mathrm{pO}_{2}(\% \mathrm{PAL})\end{array}$ & $\begin{array}{l}10 \text { percentiles } \\
\mathrm{pO}_{2}(\% \mathrm{PAL})\end{array}$ & $\begin{array}{l}15 \text { percentiles } \\
\left.\mathrm{pO}_{2} \text { ( } \% \mathrm{PAL}\right)\end{array}$ \\
\hline Paleoproterozoic & 2500-1600 Ma & 1.0 & 1.6 & 2.4 \\
\hline Mesoproterozoic_early Neoproterozoic & $1600-650 \mathrm{Ma}$ & 0.8 & 1.6 & 2.4 \\
\hline middle Paleozoic to modern & 400-0 Ma & 100 & 100 & 100 \\
\hline
\end{tabular}

Because secondary processes such as diagenesis and silicate phase contamination drive $\mathrm{Ce} / \mathrm{Ce}^{*}$ towards unity, we focus on the lowermost values. In addition, the variation recorded within a single time period is expected to reflect the potential redox diversity in depositional environments. For example, $\mathrm{Ce} / \mathrm{Ce} *$ in modern oceans reflects much higher dissolved oxygen in shallowwater masses than in waters below the redoxcline ${ }^{28}$. Thus, we selected lowest $\mathrm{Ce} / \mathrm{Ce}^{*}$ values for a given time interval and considered the statistical distribution of sample numbers. We then used the relationship between $\mathrm{Ce} / \mathrm{Ce} *$ in carbonates and $\mathrm{pO}_{2}$ to estimate atmospheric oxygen levels in the past.

We adopted two approaches to estimate the atmospheric oxygen levels: 1) A discrete method that divides data into four groups (Supplementary Discussion) and 2) a smoothing method using 100 Myr time intervals. The results of the first method are given in Table 1 , where we use the 10 th percentiles of $\mathrm{Ce} / \mathrm{Ce}^{*}$ data for the four individual age groups (2500-1600, 1600-650, $650-400$, and $400-0 \mathrm{Ma}$ ) to calculate most probable $\mathrm{pO}_{2}$ for these intervals. Groups were defined to reflect the current understanding of $\mathrm{pO}_{2}$ evolution through time (see Supplementary Discussion for details), and we additionally explored discrete intervals in the early Phanerozoic (Cambrian-Silurian) and late Phanerozoic (Devonian and later) in an attempt to test existing hypotheses concerning the increase in atmospheric oxygen that resulted from the mid-Paleozoic rise of land plants ${ }^{21}$. Moreover, each group contains samples from at least two different formations to minimize sampling bias. This method suggests that $\mathrm{pO}_{2}$ hovered around 1.6\% PAL for most of the Proterozoic Eon. Calculations using the 5th and 15th percentiles of Ce anomaly data provide lower and upper bounds of $1.0 \%$ and $2.4 \% \mathrm{PAL}$, respectively, for $\mathrm{pO}_{2}$ (Table 1 ). We note that the difference between the modern and the past $\mathrm{Ce}$ anomaly values determines the magnitude of the oxygen level estimate. Thus, the $\mathrm{pO}_{2}$ estimate given by 5 th percentiles of Ce anomaly data is lower than that calculated from 15 th percentiles of data.

For the second method, we used the lowest $10 \%(<10$ th percentiles) of values for each $100 \mathrm{Myr}$ interval to estimate the atmospheric oxygen level from the $\mathrm{Ce} / \mathrm{Ce}^{*}$ data for each group; uncertainties are given at the $95 \%$ confidence level. This method improves time resolution, but results in greater uncertainties. The $\mathrm{pO}_{2}$ curve in Fig. 2 shows the atmospheric oxygen trend inferred from the $\mathrm{Ce} / \mathrm{Ce}^{*}$ data. We have compared our modeling results 


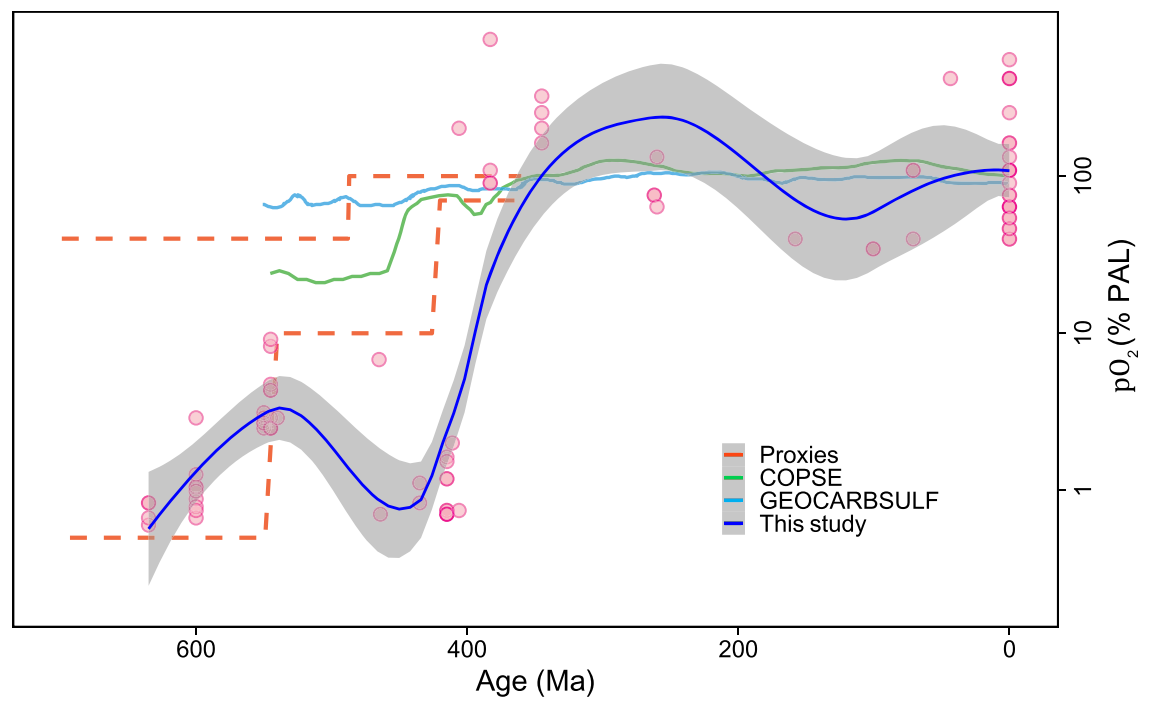

Fig. 3 The estimated partial pressure of atmospheric oxygen level $\mathrm{pO}_{2}(\% \mathrm{PAL})$ during the Phanerozoic Eon compared to the results of other

studies $^{\mathbf{1 2}, \mathbf{3 3}}$. The blue line shows our best estimate, and the gray field indicates the upper and lower bounds based on $95 \%$ confidence level using the LOESS curve fitting method. The $\mathrm{pO}_{2}$ was calculated using the lowest $10 \%$ of all carbonate $\mathrm{Ce} / \mathrm{C} \mathrm{e}^{\star}$ data for 100 Ma intervals during the Phanerozoic Eon

during the Phanerozoic Eon with other models and proxy results (Fig. 3). The $\mathrm{pO}_{2}$ curve developed in this study is consistent with previous proxy and modeling results, especially for the last $\sim 400$ million years ${ }^{12}$. For the earlier Paleozoic Era (541-400 Ma), our atmospheric oxygen level estimate is lower than other estimates $^{12,33}$, perhaps reflecting biases associated with limited sample numbers for this time interval.

Both of these methods provide an estimate of $\sim 1$ to $2 \%$ PAL for atmospheric oxygen level from the direct aftermath of the GOE to the NOE (Fig. 2 and Table 1). We do not use $\mathrm{Ce} / \mathrm{Ce}^{*}$ to quantify $\mathrm{pO}_{2}$ prior to the GOE because of its low sensitivity under anoxic conditions. Although temperature affects the solubility of $\mathrm{O}_{2}$ in seawater, we do not consider variation in temperature in Earth's history as there is little consensus on the magnitude of temperature change. Lower $\mathrm{pH}$, however, could potentially increase $\mathrm{pO}_{2}$ estimates, especially for the mid-Proterozoic, when higher $\mathrm{pO}_{2}$ could have resulted in lower seawater $\mathrm{pH}^{35,36}$ (see Supplementary Discussion). This potential $\mathrm{pH}$ effect requires that our estimates of mid-Proterozoic $\mathrm{pO}_{2}$ should be considered conservative and may underestimate atmospheric oxygen levels.

Our calculated values of $\mathrm{pO}_{2}$ through time after the GOE are broadly consistent with earlier estimates, although arrived at by different means (Fig. 2). Like other studies, we see little evidence for Proterozoic oxygen increase beyond that achieved during the $\mathrm{GOE}^{37}$ until at least the Ediacaran ${ }^{2}$, where our calculations suggest that atmospheric oxygen rose, and remained above $1 \%$ PAL (Fig. 2). We do not see evidence for a significant transient atmospheric oxygen increase proposed for the GOE (e.g., see ref. ${ }^{2}$ ). However, this result could be due to our low sample density for the GOE. Our calculations suggest an EdiacaranCambrian increase in $\mathrm{pO}_{2}$ to 2-6\% PAL (Figs. 2 and 3)-near the lower end of atmospheric oxygen levels permitted by the interpreted physiology of Lower Paleozoic animals ${ }^{38}$. There also appears to be a transient decrease in atmospheric oxygen level during the Early Paleozoic, which is a time of widespread ocean subsurface anoxia, a limited abundance of skeletal animals, and repeated extinctions ${ }^{31,39}$, before reaching the near-modern atmospheric oxygen levels in the mid-Paleozoic, consistent with oxygenation linked to land-plant evolution.

While we provide atmospheric $\mathrm{pO}_{2}$ estimates comparable to previous studies ${ }^{11,12,38}$, we acknowledge some limitations of this thermodynamics-based modeling approach. First, we assume a thermodynamic equilibrium for Ce oxidation, while recognizing that $\mathrm{Ce}^{3+}$ oxidization might be kinetically limited. We note that for Ce anomaly, it is not absolute amount that was oxidized is important, but ratio of oxidized to total dissolved Ce. Oxidation rate should scale with $\mathrm{pO}_{2}$ and it is a fraction of Ce oxidized rather than absolute amount of $\mathrm{Ce}$ that would determine $\mathrm{Ce}$ anomaly. Another important assumption that we made is that oxygen content of surface seawater was in equilibrium with the overlying atmosphere. Olson et al. ${ }^{40}$ and Reinhard et al. ${ }^{41}$ proposed that oxygen oases could persist in shallow-marine environments beneath an atmosphere with low $\mathrm{pO}_{2}$ as in the mid-Proterozoic. In principle, this could mean that our estimates of early atmospheric oxygen levels are too high. We note, however, that oxygen oases in mid-Proterozoic shallow-marine environments where $P$ availability was low and deep waters were ferruginous ${ }^{41-45}$ would likely have been exceedingly limited.

Our best estimate for long-term mid-Proterozoic oxygen levels of $\sim 1$ to $2 \%$ PAL falls within the lower end of previous estimates ${ }^{46}$. The model of Zhang et al. ${ }^{3}$ infers atmospheric oxygen level between 4 and 8\% PAL. Our estimate is higher than those based on $\mathrm{Cr}$ isotopes ${ }^{8,9}$, a kinetics-based estimate using $\mathrm{Ce} / \mathrm{Ce}{ }^{* 7}$, and $\mathrm{Zn} / \mathrm{Fe}$ carbonate-based estimate of Liu et al. ${ }^{11}$. Our thermodynamics-based $\mathrm{Ce} / \mathrm{Ce}^{*}$ estimate thus supports the general view that atmospheric $\mathrm{pO}_{2}$ was one to two orders of magnitude lower than modern content in the midProterozoic ${ }^{2,6}$.

Here we present a novel approach to using the Ce anomaly $\left(\mathrm{Ce} / \mathrm{Ce}^{*}\right)$ measured in shallow-marine carbonates as a proxy for the redox evolution of Earth's near-surface environments. Because many marine carbonates were deposited in shallowmarine environments, in close contact with the atmosphere, their elemental ratios such as Ce anomaly, as well as zinc to iron ratios $^{11}$, are more likely to reflect the atmospheric redox state. Carbonates provide a continuous record back to the Proterozoic Eon, while other rock records are patchy. More importantly, research on carbonate $\mathrm{Ce} / \mathrm{Ce}^{*}$ provides a proxy to quantify atmospheric $\mathrm{O}_{2}$ throughout Earth's middle age. Although further work is needed to fully understand this promising paleo-redox proxy, carbonate-based redox proxies show great potential to expand our understanding of redox history and specifically to provide quantitative and self-consistent constraints on atmospheric oxygen levels for the early Earth. 


\section{Methods}

Analytical methods. Rare earth elements plus yttrium (REY) concentrations were measured using a Thermo Scientific ${ }^{\circ}$ iCAP-Q ICP-MS (Inductively Coupled Plasma-Mass Spectrometry) at the Carnegie Institution for Science. Approximately $5-10 \mathrm{mg}$ of micro-drilled sample powders were weighed and dissolved in $2 \mathrm{ml}$ of distilled $0.4 \mathrm{M} \mathrm{HNO}_{3}$ over $12 \mathrm{~h}$. The resulting solutions were centrifuged for $5 \mathrm{~min}$ at $\sim 5000 \times \mathrm{g}$. Then $1 \mathrm{ml}$ of the supernatant from each resultant solution was pipetted and diluted with distilled $4 \mathrm{ml} 0.4 \mathrm{M} \mathrm{HNO}_{3}$ for elemental analysis. Calibration curves were created using multielemental standards with different dilutions made from pure element solutions (Alfa Aesar ${ }^{\circledast}$ ). Both standard and sample solutions were doped with $4 \mathrm{ppb}$ indium to correct for instrumental drift. The precision of the analyses was determined by repeated analyses of an in-house carbonate standard and was typically better than $10 \%(2 \sigma)$ for rare earth elements plus yttrium (REYs).

\section{Data availability}

The authors declare that all source data supporting the findings of this study are available within the paper and its supplementary files. All relevant data are available from the authors upon request. Source data are provided with this paper.

\section{Code availability}

The authors declare that the code used to analyze and visualize the dataset can be accessed online from figshare (https://doi.org/10.6084/m9.figshare.13114379). The Figs. 2 and 3 in the paper were made using R statistical software (http://www.R-project.org/).

Received: 28 August 2020; Accepted: 3 December 2020;

Published online: 13 January 2021

\section{References}

1. Canfield, D. E. The early history of atmospheric oxygen: homage to Robert A. Garrels. Annu. Rev. Earth Planet. Sci. 33, 1-36 (2005).

2. Lyons, T. W., Reinhard, C. T. \& Planavsky, N. J. The rise of oxygen in Earth's early ocean and atmosphere. Nature 506, 307-315 (2014).

3. Zhang, S. et al. Sufficient oxygen for animal respiration 1,400 million years ago. Proc. Natl Acad. Sci. 113, 1731 (2016).

4. Shang, M. et al. A pulse of oxygen increase in the early Mesoproterozoic ocean at ca. 1.57-1.56 Ga. Earth Planet. Sci. Lett. 527, 115797 (2019).

5. Canfield, D. E. et al. Highly fractionated chromium isotopes in mesoproterozoicaged shales and atmospheric oxygen. Nat. Commun. 9, 2871 (2018).

6. Rye, R. \& Holland, H. D. Paleosols and the evolution of atmospheric oxygen: a critical review. Am. J. Sci. 298, 621-672 (1998).

7. Bellefroid, E. J. et al. Constraints on paleoproterozoic atmospheric oxygen levels. Proc. Natl Acad. Sci. 115, 8104 (2018).

8. Cole, D. B. et al. A shale-hosted Cr isotope record of low atmospheric oxygen during the proterozoic. Geology 44, 555-558 (2016).

9. Planavsky, N. J. et al. Low mid-proterozoic atmospheric oxygen levels and the delayed rise of animals. Science 346, 635-638 (2014).

10. Gilleaudeau, G. J. et al. Oxygenation of the mid-Proterozoic atmosphere: clues from chromium isotopes in carbonates. Geochem. Perspect. Lett. 2, 178-187 (2016).

11. Liu, X.-M. et al. Tracing Earth's $\mathrm{O} 2$ evolution using $\mathrm{Zn} / \mathrm{Fe}$ ratios in marine carbonates. Geochem. Perspect. Lett. 2, 24-34 (2016).

12. Lu, W. et al. Late inception of a resiliently oxygenated upper ocean. Science 361, 174 (2018).

13. Kah, L. C., Lyons, T. W. \& Frank, T. D. Low marine sulphate and protracted oxygenation of the proterozoic biosphere. Nature 431, 834-838 (2004).

14. Kamber, B. S., Bolhar, R. \& Webb, G. E. Geochemistry of late Archaean stromatolites from Zimbabwe: evidence for microbial life in restricted epicontinental seas. Precambrian Res. 132, 379-399 (2004).

15. Webb, G. E. \& Kamber, B. S. Rare earth elements in Holocene reefal microbialites: a new shallow seawater proxy. Geochim. Cosmochim. Acta 64, $1557-1565$ (2000).

16. Lawrence, M. G., Greig, A., Collerson, K. D. \& Kamber, B. S. Rare earth element and yttrium variability in South East Queensland waterways. Aquat. Geochem. 12, 39-72 (2006)

17. Bau, M., Koschinsky, A., Dulski, P. \& Hein, J. R. Comparison of the partitioning behaviours of yttrium, rare earth elements, and titanium between hydrogenetic marine ferromanganese crusts and seawater. Geochim. Cosmochim. Acta 60, 1709-1725 (1996).

18. German, C. R., Holliday, B. P. \& Elderfield, H. Redox cycling of rare earth elements in the suboxic zone of the Black Sea. Geochim. Cosmochim. Acta 55, 3553-3558 (1991).

19. Kamber, B. S., Webb, G. E. \& Gallagher, M. The rare earth element signal in Archaean microbial carbonate: information on ocean redox and biogenicity. J. Geol. Soc. 171, 745-763 (2014).
20. German, C. R. \& Elderfield, H. Application of the Ce anomaly as a paleoredox indicator: the ground rules. Paleoceanography 5, 823-833 (1990).

21. Wallace, M. W. et al. Oxygenation history of the Neoproterozoic to early Phanerozoic and the rise of land plants. Earth Planet. Sci. Lett. 466, 12-19 (2017).

22. Elderfield, H., Whitfield, M., Burton, J. D., Bacon, M. P. \& Liss, P. S. The oceanic chemistry of the rare-earth elements [and Discussion]. Philos. Trans. R. Soc. Lond. Ser. A 325, 105-126 (1988).

23. Cao, C., Liu, X.-M., Owens, J. D., Jenkyns, H. C. Late Cretaceous cerium anomalies and globally distinctive redox responses before, during and after Oceanic anoxic event 2. Paleoceanogr. Paleoclimatol. in review (202X).

24. Liu, X. M., Hardisty, D. S., Lyons, T. W. \& Swart, P. K. Evaluating the fidelity of the cerium paleoredox tracer during variable carbonate diagenesis on the Great Bahamas Bank. Geochim. Cosmochim. Acta 248, 25-42 (2019).

25. Banner, J. L., Hanson, G. N. \& Meyers, W. J. Rare earth element and Nd isotopic variations in regionally extensive dolomites from the BurlingtonKeokuk formation (Mississippian); implications for REE mobility during carbonate diagenesis. J. Sediment. Res. 58, 415-432 (1988).

26. Babechuk, M. G., Widdowson, M. \& Kamber, B. S. Quantifying chemical weathering intensity and trace element release from two contrasting basalt profiles, Deccan Traps, India. Chem. Geol. 363, 56-75 (2014).

27. Elderfield, H. \& Greaves, M. J. The rare earth elements in seawater. Nature 296, 214-219 (1982).

28. Nozaki, Y. \& Alibo, D. S. Importance of vertical geochemical processes in controlling the oceanic profiles of dissolved rare earth elements in the northeastern Indian Ocean. Earth Planet. Sci. Lett. 205, 155-172 (2003).

29. Cao, C., Liu, X.-M., Bataille, C. P. \& Liu, C. What do Ce anomalies in marine carbonates really mean? A perspective from leaching experiments. Chem. Geol. 532, 119413 (2020).

30. Tostevin, R. et al. Effective use of cerium anomalies as a redox proxy in carbonate- dominated marine settings. Chem. Geol. 438, 146-162 (2016).

31. Wallace, M. W., Hood, Av. S., Fayle, J., Hordern, E. S. \& O'Hare, T. F. Neoproterozoic marine dolomite hardgrounds and their relationship to cap dolomites. Precambrian Res. 328, 269-286 (2019).

32. Webb, G. E., Nothdurft, L. D., Kamber, B. S., Kloprogge, J. T. \& Zhao, J.-X. Rare earth element geochemistry of scleractinian coral skeleton during meteoric diagenesis: a sequence through neomorphism of aragonite to calcite. Sedimentology 56, 1433-1463 (2009).

33. Sperling, E. A. et al. The global record of iron geochemical data from Proterozoic through Paleozoic basins. Nature 523, 451-454 (2015).

34. Dahl, T. W. et al. Devonian rise in atmospheric oxygen correlated to the radiations of terrestrial plants and large predatory fish. Proc. Natl Acad. Sci. USA 107, 17911-17915 (2010).

35. Halevy, I. \& Bachan, A. The geologic history of seawater pH. Science 355, 1069 (2017).

36. Krissansen-Totton, J., Arney, G. N. \& Catling, D. C. Constraining the climate and ocean $\mathrm{pH}$ of the early Earth with a geological carbon cycle model. Proc. Natl Acad. Sci. 115, 4105 (2018).

37. Kah, L. C. \& Bartley, J. K. Protracted oxygenation of the Proterozoic biosphere. Int. Geol. Rev. 53, 1424-1442 (2011).

38. Sperling, E. A., Knoll, A. H. \& Girguis, P. R. The ecological physiology of Earth's second oxygen revolution. Annu. Rev. Ecol. Evol. Syst. 46, 215-235 (2015).

39. Gill, B. C. et al. Geochemical evidence for widespread euxinia in the Later Cambrian ocean. Nature 469, 80-83 (2011).

40. Olson, S. L., Kump, L. R. \& Kasting, J. F. Quantifying the areal extent and dissolved oxygen concentrations of Archean oxygen oases. Chem. Geol. 362, 35-43 (2013).

41. Reinhard, C. T., Planavsky, N. J., Olson, S. L., Lyons, T. W. \& Erwin, D. H. Earth's oxygen cycle and the evolution of animal life. Proc. Natl Acad. Sci. 113, 8933 (2016).

42. Canfield, D. E. \& Raiswell, R. The evolution of the sulfur cycle. Am. J. Sci. 299, 697-723 (1999).

43. Crockford, P. W. et al. Triple oxygen isotope evidence for limited midProterozoic primary productivity. Nature 559, 613-616 (2018).

44. Laakso, T. A., Sperling, E. A., Johnston, D. T. \& Knoll, A. H. Ediacaran reorganization of the marine phosphorus cycle. Proc. Natl Acad. Sci. 117, 11961 (2020).

45. Reinhard, C. T. et al. Evolution of the global phosphorus cycle. Nature 541, 386-389 (2017).

46. Kump, L. R. The rise of atmospheric oxygen. Nature 451, 277-278 (2008),

\section{Acknowledgements}

We are grateful to Tim Mock and Mary Horan for their assistance with the geochemical analyses at the Carnegie Institution for Science. We thank Larry Benninger, Cheng Cao, and Jonathan Lees for helpful discussion and Mehrnaz Siahi for sharing samples. X.-M.L. acknowledges funding support from the NSF CAREER Award (EAR-1848153) and DOD Army Research Office Grant (W911NF-17-2-0028). A.H.K. acknowledges support from 
the Templeton Foundation. R.M.H. thanks the Alfred P. Sloan Foundation, the Keck Foundation, the Templeton Foundation, and a private foundation for support of research on data-driven discovery in mineralogy and on the co-evolving geosphere and biosphere. R.M.H. also thanks NASA ENIGMA program; any opinions, findings, or recommendations expressed herein are those of the authors and do not necessarily reflect the views of the National Aeronautics and Space Administration. A.B. acknowledges NSERC Discovery and Accelerator grants.

\section{Author contributions}

X.-M.L. designed the project. L.C.K., A.H.K., H.C., A.B., and B.H. provided samples. X.-M.L. performed the experiments, statistical analyses, and did the model developmen with C.W. All authors contributed to the interpretation of the results and writing of the manuscript.

\section{Competing interests}

The authors declare no competing interests.

\section{Additional information}

Supplementary information is available for this paper at https://doi.org/10.1038/s41467020-20484-7.

Correspondence and requests for materials should be addressed to X.-M.L.
Peer review information Nature Communications thanks Eva Stüeken and Malcolm Wallace for their contributions to the peer review of this work. Peer review reports are available.

Reprints and permission information is available at http://www.nature.com/reprints

Publisher's note Springer Nature remains neutral with regard to jurisdictional claims in published maps and institutional affiliations.

(C) Open Access This article is licensed under a Creative Commons Attribution 4.0 International License, which permits use, sharing, adaptation, distribution and reproduction in any medium or format, as long as you give appropriate credit to the original author(s) and the source, provide a link to the Creative Commons license, and indicate if changes were made. The images or other third party material in this article are included in the article's Creative Commons license, unless indicated otherwise in a credit line to the material. If material is not included in the article's Creative Commons license and your intended use is not permitted by statutory regulation or exceeds the permitted use, you will need to obtain permission directly from the copyright holder. To view a copy of this license, visit http://creativecommons.org/ licenses/by/4.0/.

(C) The Author(s) 2021 